\title{
Are tick populations really less variable and should they be?
}

\author{
Larry R. Hilburn and \\ Paul W. Sattler
}

U.S. Livestock Insects Laboratory, Agricultural Research Service, U.S. Department of Agriculture Kerrville, TX 78029-0232, USA

Empirical evidence from electrophoretic examinations of Metastriate ticks does not support the prediction that these ectoparasites necessarily have low levels of genetic variability within populations and large interpopulation differences. In part, the failure of the theory to produce a parsimonious prediction seems to stem from the use of an inappropriate model based on spatial environmental heterogeneity. The experimental data are better explained in terms of host mobility, tick population size, and the degree of host specificity of the tick.

\section{INTRODUCTION}

Recently, Bull et al. (1984) reported on their test of Price's (1977) predictions that parasites would exhibit low levels of genetic variability within populations and high levels of variation between populations. They analysed enzymes electrophoretically in 65 populations representing six Australian tick species on the genera Aponoma and Amblyomma. The values they reported for average heterozygosity per individual $(h)$ were 0 per cent for Ap. undatum, 1.7 per cent for Ap. fimbriatum, 2.5 per cent for Ap. hydrosauri, 1.6 per cent for $A m b$. limbatum, $2 \cdot 3$ per cent for Amb. albolimbatum, and a low, but uncalculated, value for a new, undescribed species of Amblyomma. They interpreted their results as a confirmation of Price's (1977) model as it pertains to the levels of intrapopulation variability maintained in parasite populations. However, they found that genetic distances (Nei, 1972) between conspecific populations of reptile ticks were very low, less than 0.06 . The Nei distance statistic assumes values between 0 , when the samples being compared are genetically identical, and infinity, when the samples share no electromorphs. For reference, comparisons between conspecific samples of Drosophila yield distance values of about 0.03 ; between subspecies distances are about $0 \cdot 23$; and between full species the distances are about 1.04 (Ayala, 1975). Close genetic similarity observed between populations of parasites is not predicted by Price's (1977) model.

The values of heterozygosity and genetic distance reported by Bull et al. (1984) compare well with values obtained on the soft ticks Ornithodoros erraticus and O. sonrai (Wallis and Miller, 1983). Wallis and Miller (1983) analysed two populations of $O$. erraticus and one of $O$. sonrai electrophoretically for nine enzymes using horizontal starch gel procedures. Heterozygosity values obtained for the $O$. erraticus samples were $5 \cdot 5$ per cent $(N=15-16$, depending on the eyzyme) and $3 \cdot 3$ per cent $(N=$ 20-25). For the $O$. sonrai sample $(N=11)$ the heterozygosity value was $2 \cdot 7$ per cent. The genetic distance between the two geographic samples of $O$. erraticus (not reported, but calculated by us from data in the paper) was 0.017 , a small value compared with the interspecific distance between $O$. erraticus and $O$. sonrai reported as $0 \cdot 600$.

Two enzymes of Ixodes ricinus studied by Healy $(1979 a, b)$ were more heterozygous and did not conform to the patterns presented by the other two studies. The average heterozygosity reported for $\alpha$-glycerophosphate dehydrogenase from samples of 5 temporal and geographic populations was $53 \cdot 3$ per cent \pm 1.0 per cent ( $h \pm$ S.D.; $N=111 \cdot 4$, range 80-187) (Healy 1979b), and the heterozygosity value we calculated as the arithmetic mean of data presented for phosphoglucose mutase (Healy $1979 a)$ was 66.9 per cent \pm 2.4 per cent $(N=83.4$, range 65-109). However, Healy was reporting 
genetic studies and must have worked with the most polymorphic enzymes. Despite this consideration, Bull et al. (1984) point out Healy's results and warn that the data from reptile ticks may not be representative of ticks generally.

Over the past two years we have collected data on levels of electrophoretically detectable genetic variation found in populations of ticks infesting livestock. Using starch gel electrophoresis, we have examined natural populations or recently established colonies of three species of Amplyomma and a species of Boophilus ticks found in North America. In all cases, 21 or 23 enzymes were examined and sample sizes were ustally greater than 50 ticks. The average heterozygosity value obtained for eight populations of B. microplus from Mexico, Puerto Rico, and southern Texas $(N=74$, range: $27-125)$ was $9 \cdot 15$ per cent \pm 0.80 per cent (Sattler et al., in press $b$ ). Nine populations of Amb. americanum $(N=77 \cdot 8$, range: $17-151)$ had an average heterozygosity value of 8.51 per cent \pm 1.01 per cent (Hilburn and Sattler, in press). Similar average heterozygosity values have been observed in preliminary examinations of two other species: Amb. cajennense ( $h=8.81$ per cent \pm 2.09 per cent; $N=28.5$; range $=18-39$ ) and $A m b$. maculatum $(h=9 \cdot 23$ per cent, $N=24)$. These heterozygosities compare more favorably with Nevo's (1978) average heterozygosity in invertebrates of 11.23 per cent than do values obtained in other ticks. If one omits data from the extensively studied Drosophila species and considers only those studies of invertebrates in which sample sizes and numbers of enzymes examined were comparable to ours, Nevo (1978) reports a heterozygosity value of 0.088 . Using Nevo's two values for comparison, our data do not suggest that the ticks we examined have greatly reduced levels of genetic variability when compared to other invertebrates.

Our observations on the degree of genetic divergence between conspecific populations of livestock ticks do conform to those reported by Bull et al. (1984) and Wallis and Miller (1983). Our eight samples of B. microplus yielded a Nei genetic distance of 0.016 (Sattler et al., in prep. $b$ ), between two samples of $A m b$. cajennense the distance was $0 \cdot 016$ (unpublished) and among the nine populations of Amb. americanum the average distance was 0.008 (Hilburn and Sattler, in prep.). The values observed among the studies on ticks clearly suggest an absence of genetic divergence between local populations over large geographic areas. This result is totally unexpected from Price's (1977) model as tested by Bull et al. (1984).
Since the different studies done on ticks to date tend to agree concerning levels of interpopulation divergence, but disagree concerning levels of intrapopulation heterozygosity, the question is, which of these data are representativie of the level of genetic variation in ticks in general. Bull et al. (1984) give three reasons why their heterozygosity estimates might be low. First, their sample sizes were quite small. Only two samples out of 65 had sizes greater than 20 and most had fewer than 10 individuals. Small sample size was also a weakness of Wallis and Miller's (1983) study in which fewer than 25 individuals were examined from any population.

Secondly, the choice of enzymes for study may have biased their results toward low heterozygosity values (Simon and Archie, 1985). For instance, in our studies on Amblyomma and Boophilus species on livestock, esterases and two isozymes of aconitase had consistently high variability. Neither of these enzymes was examined by Bull et al. (1984) or Wallis and Miller (1983). Also there is a possibility that some of the enzymes reported by Bull et al. (1984) might be sex-linked. Since most of the species with which they worked have X0 karyotypic sexual dimorphisms in the males (Oliver, 1977) and they examined only males, sex-linked genes would be scored as homozygotes and would not contribute to heterozygosity estimates. Bull et al. (1984) refer to phosphoglucose isomerases as probably being sex-linked in the Australian ticks. Our mapping studies on livestock ticks have shown that this enzyme is sex-linked in both B. microplus (Sattler et al., in prep. $a$ ) and Amb. americanum (Sattler and Hilburn, unpub. data). In addition, adenylate kinase is X-linked in Amb. americanum and one locus of glutamate oxalacetate transaminase is X-linked in B. microplus. These enzymes were examined in the previous studies, but if either is also X-linked in the Australian ticks, heterozygosity values would have been increased if females had been examined.

Finally, the electrophoretic conditions used to resolve allozyme differences have a profound effect on the number of electromorphs observed. Since neither Bull et al. (1984) nor Wallis and Miller (1983) give detailed descriptions of their procedures, it is not possible to compare their methods with ours. However, in the case of the former study, cellulose acetate generaily does not resolve small migration differences as well as starch or acrylamide support media.

For the reasons above, we believe that the heterozygosity values reported by previous authors may be artificially low. Our data suggest that ticks 
are not as homozygous as has been formerly apparent. These empirical results differ from the expectations of Frice's (1977) model with regard both to predicted levels of heterozygosity within populations and to extent of divergence between populations. We would argue that Price was correct when he warned that his model was inappropriate for describing strategies in ticks, at least as the model was stated by Bull et al. (1984), and that the observations made on genetic variation among ticks are better explained by aspects of tick biology other than spatial heterogeneity of their environment. Since the species examined by Bull et al. (1984) and by us are Metastriate ticks (hard ticks except Ixodes), we limit our discussion to that group.

In stating their test of Price's model, Bull et al. (1984) defined their patches of environmental alternatives as being the habitat presented by the host and the habitat off the host. They state that these patches are coarse-grained, in the sense of MacArthur and Levins (1964), and very different in the physiological demands imposed on the organism. They then derive the best survival strategy for an organism in such a heterogeneous environment according to the guidelines of Levins (1968). However, implicit in Levin's model (1962, $1963,1968)$ is the assumption that an organism has a non-zero fitness in both of the alternative patches. Among hard ticks the only source of nourishment is the series of blood meals they obtain from their hosts. Among most of the Metastriate ticks, spermatogenesis is not initiated until the beginning of feeding by the adult (Oliver 1982). In general, female hard ticks do not mate or produce eggs unless they have fed (Diehl et al., 1982). This intimate relationship between gametogenesis and feeding is explained as a specialized adaptation to conserve reproductive potential until conditions are best for completing mating and reproduction. Practically, this physiological adaptation forces a hard tick to pass between the off-the-host patch and the on-the-host patch to reproduce. Thus, while adaptations to the off-the-host patch assist in the survival of the tick, its fitness will be zero in this habitat unless a means of reproducing independent of a host is evolved. Interestingly, certain Australian hard ticks (including Ap. hydrosauri examined by Bull et al., 1984) are exceptional in being able to initiate spermatogenesis prior to adult feeding (Oliver and Stone, 1983). However, neither off-the-host mating nor female autogeny was reported, so this adaptation seems to result from selection to shorten premating time on the host rather than to exploit the habitat off the host.
Since the ecological dichotomy stated by Bull et al. (1984) does not meet the assumptions of Levin's (1968) model, the expectations derived from that model must be suspect.

A more pertinent model has been described by Emlen (1973). In this model the environmental heterogeneity perceived by the tick is temporal rather than spatial. The tick moves from a hospitable patch to a less hospitable patch one or more times during its lifetime. If the movement between patches occurs infrequently and at unpredictable intervals, then the optimum strategy is to be monomorphic, specialized to survive in the hospitable patch, and able to escape the inhospitable patch by migrating, hibernating, encysting, etc. This is clearly the strategy assumed by hard ticks. Off the host, unless they are actively host-seeking, ticks are inactive, hide in protected micro-habitats, and live on their last bloodmeal. However, Emlen (1973) warns that this overall pattern can be complicated if the hospitable habitat contains spatial heterogeneity.

If an exploitable spatial component exists in the heterogeneous environment of hard ticks, it results from the tick's ability to utilize several hosts. If substantially different adaptations are required to exploit these various hosts, then the model derived and tested by Bull et al. (1984) pertains: a species' best strategy is a specialized phenotype, discreet specialized morphs, and a high degree of genetic homozygosity. However, if the difference between hosts is not great compared with the physiological tolerance of the tick, it no longer matters whether the parasites utilize different hosts frequently or infrequently, for in either case the strategy is the same: monomorphism for a genotype adapted to conditions intermediate between the extremes represented by the alternative hosts (Levins, 1968).

An important warning made by Levins (1968) was that the phenotypic monomorphism demanded by his theory need not imply genic monomorphism. The best adapted phenotypic morph might be the one produced by the heterozygous phenotype; hybrid vigor and other forms of heterosis would be examples. The only requirement would be that the phenotypic advantage of heterozygotes be sufficient to overcome the segregational load inherent in heterozygous populations. Such an advantage would be possible if the presence of different allozymes broadened the range of physiological tolerance of the tick sufficiently to encompass the opportunities offered by more than one common, exploitable host (Hochachka and Somero, 1973). Thus, an 
argument could be made that, for instance, generalist feeders like $A m b$. americanum, Amb. cajennense, or I. ricinus (using the host specifications assigned by Hoogstraal and Aeschlimann, 1982) might be expected to exhibit greater heterozygosity than the more host-specific reptile ticks from Australia. However, B. microplus is also classified by Hoogstraal and Aeschlimann (1982) as hostspecific and exhibits no greatly reduced heterozygosity compared to Amb. americanum (Sattler et al., in press; Hilburn and Sattler, in press). We are left with the conclusion that neither the levels of intrapopulation genetic heterogeneity nor interpopulation diversity actually observed in ticks are predicted by arguments based only on environmental heterogeneity.

\section{CONCLUSION}

We suggest, instead, that population size and migration are more important factors in determining genetic heterozygosity in ticks. If we accept the Australian tick data as representative, or even slightly low, then, when comparing those heterozygosity levels with those we observed in livestock ticks, we would attribute the differences to the smaller population sizes observed among the reptile ticks. Such low population sizes and the infrequency of a host-specific tick finding an appropriate host would increase inbreeding, which in turn would increase homozygosity. Among livestock ticks where hosts are abundant, particularly among those ticks that are not host-specific, inbreeding would be rarer and the population would more closely approach panmixia. It must be emphasized here that the degree to which a species is compelled to inbreed is the important factor. Given an enzyme polymorphism with the same adaptive value for 2 taxa of ticks, the polymorphism will be less likely to be stabilized in a tick that undergoes inbreeding than in one that is more panmictic (Levin, 1968). Thus, species with small population sizes should tend to be less variable than those with large population sizes.

The degree to which populations diverge genetically is primarily determined by the amount of gene flow. Even infrequent exchange of genes between populations will prevent significant interpopulation divergence as long as the exchange is not solely between near neighbor populations having very similar gene frequencies (Crow and Kimura, 1970). Among the ticks we examined, hosts are large, mobile mammals, including cattle, deer, and certain carnivores, all of which can disperse ticks rather broadly. Moreover, the longdistance transport of livestock and pets within the ranges of these species and the large population sizes encountered throughout their distributions should act to reduce interpopulation differentiation.

The role of selection in maintaining the species identity in ticks is more difficult to assess from the enzyme data but must be important. Even though the reptile ticks, with their low population numbers and hosts with limited mobility, would seen to be ideal candidates for the production of local races, it might be expected that their host-specific feeding behavior would impose so strong a stabilizing selection on their phenotype that it would counteract any effects resulting from random drift. In fact, Bull et al. (1984) observed remarkable divergence between local populations in only three cases, and in none of these cases could they rule out geographic isolation followed by post-divergence, secondary contact.

In summary, empirical evidence from electrophoretic examinations to tick species does not support the expectation that ticks have low levels of genetic variability within populations and high levels of interpopulation differences. In part, the failure of the theory to produce adequate predictions seems to stem from the use of an inappropriate model. Our work suggests that the levels of genetic variation within and between populations of hard ticks can be framed in a model incorporating environmental heterogeneity. However, the patches of alternative resources are not those offand on-the-host, but the different potentially exploitable hosts. The grain is defined by host abundance and mobility as well as the degree of host specificity characteristic of the tick. Phenotypic homeostasis may also be important, but the effects of this factor are more difficult to deduce from data on natural populations.

\section{REFERENCES}

AYALA, F. J., TRACEY, M. L., HEDGECOCK, D. AND RICHMOND, R. C. 1975. Genetic differentiation during the speciation process in Drosophila. Evolution 28, 576-592.

BULL, C. M., ANDREWS, R. H. AND ADAMS, M. 1984. Patterns of genetic variation in a group of parasites, the Australian reptile ticks. Heredity, 53, 509-525.

CROW, J. F. AND KIMURA, M. 1970. An Introduction to Population Genetics Theory. Harper \& Row, Publishers, New York. $591 \mathrm{pp}$.

DIEHL, P. A., AESCHLIMANN, A. AND OBENCHAIN, F. D. 1982. Tick reproduction: oogenesis and oviposition. The Physiology of Ticks. F. D. Obenchain and R. Galun (eds.), Pergamon Press, New York. 277-350. 
EMLEN, J. M. 1973. Ecology: An evolutionary approach. Addison-Wesley Publishing Company, Reading, Massachusetts. 493 pp.

HEALY, J. A. $1979 a$. Phosphoglucomutase polymorphism in the tick Ixodes ricinus. Parasitology, 78, 7-18.

HEALY, J. A. $1979 b$. Analysis of $\alpha$-glycerophosphate dehydrogenase variability in the tick Ixodes ricinus (Acari: Ixodidae). Genetica, 50, 19-30.

HILBURN, L. R. AND SATTLER, P. W. Genetic variability in natural populations of Amblyomma americanum (Acari: Ixodidae). Heredity. (In press).

HOCHACHKA, P. W. AND SOMERO, G. N. 1973. Strategies of Biochemical Adaptation. W. B. Saunders Company, Philadelphia. 358 pp.

HoOgStraAl, H. AND AESChlimANN, A. 1982. Tick-host specificity. Bull. Soc. Entomol. Suisse, 55, 5-32.

LEVINS, R. 1962. Theory of fitness in a heterogeneous environment. I. The fitness set and adaptive function. Amer. Natur., 96, 361-373.

LEVINS, R. 1963. Theory of fitness in a heterogeneous environment. II. Developmental flexibility and niche selection. Amer. Natur., 97, 75-90.

LEVINS, R. 1968. Evolution in Changing Environments. Princeton University Press, Princeton, NJ. 120 pp.

MACARTHUR, R. AND LEVINS, R. 1964. Competition, habitat selection, and character displacement in a patchy environment. Proc. N.A.S., 51, 1207-1210.
NEI, M. 1972. Genetic distance between populations. Am. Nat., 106, 283-292.

NEVO, E. 1978. Genetic variation in natural populations: patterns and theory. Theor. Pop. Biol. 13, 121-177.

Oliver, J. H., JR. 1977. Cytogenetics of mites and ticks. Ann. Rev. Entomol. 22, 407-429.

OLIVER, J. H., JR. 1982. Tick reproduction: sperm development and cytogenetics. In The Physiology of Ticks. F. D. Obenchain and R. Galun (eds.), Pergamon Press, New York. 245-275.

OLIVER, J. H., JR. AND STONE, B. F. 1983. Spermatid production in unfed, Metastriata ticks. J. Parasitol. 69, 420-421.

PRICE, P. W. 1977. General concepts on the evolutionary biology of parasites. Evolution, 31, 405-420.

SATTLER, P. W., HILBURN, L. R. AND DAVEY, R. B. Linkage relationships among twelve isozyme loci in cattle fever ticks on the genus Boophilus. J. Heredity. (In press).

SATTLER, P. W., HILBURN, L. R., DAVEY, R. B., GEORGE, J. E. AND ROJAS AVALOS, J. B. Genetic similarity and variability between natural populations and laboratory colonies of North American Boophilus (Acari: Ixodidae). (In press).

SIMON, C. AND ARCHIE, J. 1985. An empirical demonstration of the liability of heterozygosity estimates. Evolution, 39, 463-467.

WALLIS, G. P. AND MILLER, B. R. 1983. Electrophoretic analysis of the ticks Ornithodoros (Pavlovskyella) erraticus and $O$. (P.) sonrai (Acari: Argasidae). J. Med. Entomol., 20, 570571 . 